\title{
Challenges to the adoption of risk algorithms for colorectal cancer screening programmes: perspectives for future research
}

\author{
JJ Huang, MSc, Jason LW Huang *, MD \\ The Jockey Club School of Public Health and Primary Care, Faculty of Medicine, The Chinese University of Hong Kong, Shatin, \\ Hong Kong \\ *Corresponding author: jasonlwhuang@link.cuhk.edu.hk
}

Hong Kong Med J 2017;23:661-3

DOI: 10.12809/hkmj177058

Colorectal cancer (CRC) is the third most common cancer worldwide and accounts for $10 \%$ of all cancer new cases. ${ }^{1}$ There is concrete evidence for the effectiveness of screening in reducing CRC-related mortality. ${ }^{2}$ In some developed nations such as the US, colonoscopy has been used as a primary screening tool. ${ }^{3}$ Because not all countries are equipped with adequate colonoscopy resources for populationbased screening, it is recommended for individuals with increased risk for CRC only. ${ }^{4}$ Hence in many countries, the concept of risk-based screening is gaining appeal, particularly the use of scores to riskstratify subjects and classify screening participants as average-risk or high-risk. A prominent example is the risk score devised and validated by the AsiaPacific CRC working group, named the Asia-Pacific Colorectal Screening (APCS) score. ${ }^{5}$ It uses age, gender, smoking habit, and presence of a history of CRC in a first-degree relative to identify highrisk individuals (score 4-7 out of 7) who are more likely to benefit from colonoscopy screening due to the higher yield of advanced colorectal neoplasia. Subjects who score 0-3 are advised to undertake faecal occult blood tests. The APCS score has a high level of validity and was developed following rigorous statistical analysis. ${ }^{6}$ Other validated risk scores have been constructed using similar methods and have potential for use in clinical practice. ${ }^{7,8}$

Yeoh et $\mathrm{al}^{5}$ also identified some issues related to the application of the APCS score. The objective of this commentary is to discuss the potential challenges and perspectives for future research into risk-based CRC screening.

First, not all known risk factors for CRC can be incorporated into the model due to practical difficulties. Some information is difficult or too time-consuming to be accurately collected in a clinic scenario, such as dietary habits and level of physical activity. Second, increasing the number of variables will inevitably reduce the practical utility of the scoring systems, and not all risk factors possess good predictive value. This might explain why some scoring systems suggest a need for further work, ${ }^{9,10}$ as several algorithms have relatively modest concordance statistics, barely exceeding the acceptable level of "satisfactory" (0.6-0.7). Furthermore, the derivation process of these scoring systems usually employs a split-cohort strategy without external validation. Subsequent validation in other populations might not result in similar discriminatory capabilities. ${ }^{11}$ Third, there are concerns about the generalisability of these scores in people residing in different regions around the world. It is well recognised that the prevalence and distribution of advanced colorectal neoplasia differ for different ethnicities. Fourth, in order for a local government to use these risk scoring tools, their efficiency and cost-effectiveness must be evaluated in the local context. Formal cost-effectiveness analysis based on various risk factors should be performed for each population to be served. ${ }^{12-14}$ There are also concerns about the acceptability and distributive justice of such an approach. Whilst some unhealthy lifestyle habits such as smoking, drinking alcohol, and consuming red meat are risk factors for CRC, it is hard to justify why people 'choosing these lifestyle habits' deserve to be screened by a more expensive screening option such as colonoscopy.

These risk scores are scientifically robust and nicely constructed. Nonetheless, at the health care system level, their generalisability remains uncertain. The different opinions of various stakeholders also complicate matters - the perception of risk is subjective and it is likely that screening participants will be destined to undergo colonoscopy despite having an average risk as assessed by the risk scores, not because they wish to.

Prior to 2016, there was no population-based CRC screening programme in Hong Kong. In response to the increasing health burden posed by $\mathrm{CRC}$, the government has since launched a 3-year subsidised, CRC screening pilot programme in the population for asymptomatic individuals aged 61 to 70 years. The screening modality uses a 2-yearly, two-specimen faecal immunochemical test, followed by colonoscopy if any one sample is positive. This pilot programme collects data on its feasibility and 
cost-effectiveness. It is yet to be discussed whether a risk-based approach can be incorporated into future programmes.

We believe each country will need a screening programme tailored to the characteristics of its own population. Nonetheless, collaboration among specialist personnel may be helpful to establish several initiatives. First, we need to enhance the discriminatory capability of screening tests. Currently the predictive variables are presented as categorical variables in most scoring systems that are more user-friendly and more convenient. Appropriate statistical adjustments could be made to obtain more precise weightings for each risk factor, and this might increase the concordance statistics of the algorithm.

Second, development of non-invasive biomarkers affordable to the general public should be an important focus. There is increasing evidence to support the use of newer modalities, such as computed tomographic colonography and faecal DNA testing. These may serve as useful tools in the screening of CRC. ${ }^{15}$ Despite the potential risk of radiation exposure, the benefits outweigh potential harm when computed tomographic colonography is used in CRC screening. ${ }^{16} \mathrm{~A}$ multi-target faecal DNA test that detects circulating methylated septin 9 gene DNA has also been approved for CRC screening. ${ }^{17}$ Magnetic resonance colonography and capsule endoscopy are mainly used for diagnosis rather than screening. ${ }^{18,19}$ Although magnetic resonance colonography does not expose the individual to radiation and requires no sedation, use of intravenous contrast agent is required. ${ }^{20}$ Capsule endoscopy is non-invasive and also requires no sedation but the bowel preparation is more complicated than that required for colonoscopy. ${ }^{21} \mathrm{~A}$ recent report showed that faecal quantification of Fusobacterium nucleatum could be a useful supplement to faecal immunochemical test in the diagnosis of CRC and advanced adenoma. This non-invasive approach may improve the screening accuracy of current faecal immunochemical test. ${ }^{22}$

Third, effective education programmes for the general public about the risk of CRC should be formulated. In order for risk-based screening to be efficient, the effectiveness and sustainability of health education about the various risk factors for CRC should be enhanced in order to heighten community awareness. ${ }^{23}$ Acceptability, perception, attitude, and satisfaction of risk-based screening should also be evaluated. Previous studies have identified various barriers to CRC screening, including economic concerns, limited access to screening services, screening-induced discomfort, perceived bodily harm, embarrassment, and anxiety induced by screening. ${ }^{24}$ Individuals at high risk of CRC who are targeted for screening should have their attitude and perception identified in a systematic manner under a theoretical framework, such as the health belief model. ${ }^{25}$

Lastly, cost-effectiveness analysis of competing screening strategies in different patient groups should be performed in different settings. This warrants further research funding, particularly in population groups at high risk of CRC, including patients with medical conditions such as non-alcoholic fatty liver disease, diabetes, and metabolic syndrome.

\section{References}

1. Siegel RL, Miller KD, Fedewa SA, et al. Colorectal cancer statistics, 2017. CA Cancer J Clin 2017;67:177-93.

2. Sung JJ, Ng SC, Chan FK, et al. An updated Asia Pacific Consensus Recommendations on colorectal cancer screening. Gut 2015;64:121-32.

3. Rex DK, Boland CR, Dominitz JA, et al. Colorectal cancer screening: Recommendations for physicians and patients From the U.S. Multi-Society Task Force on Colorectal Cancer. Gastroenterology 2017;153:307-23.

4. Wong MC, Wong SH, Ng SC, Wu JC, Chan FK, Sung JJ. Targeted screening for colorectal cancer in high-risk individuals. Best Prac Res Clin Gastroenterol 2015;29:94151.

5. Yeoh KG, Ho KY, Chiu HM, et al. The Asia-Pacific Colorectal Screening score: a validated tool that stratifies risk for colorectal advanced neoplasia in asymptomatic Asian subjects. Gut 2011;60:1236-41.

6. Sung JJ, Wong M, Lam TY, et al. A modified colorectal screening score for prediction of advanced neoplasia: a prospective study of 5,744 subjects. J Gastroenterol Hepatol 2017 May 31. Epub ahead of print.

7. Wong MC, Lam TY, Tsoi KK, et al. A validated tool to predict colorectal neoplasia and inform screening choice for asymptomatic subjects. Gut 2014;63:1130-6.

8. Imperiale TF, Monahan PO, Stump TE, Glowinski EA, Ransohoff DF. Derivation and validation of a scoring system to stratify risk for advanced colorectal neoplasia in asymptomatic adults: a cross-sectional study. Ann Intern Med 2015;163:339-46.

9. Wong MC, Ching JY, Chan VC, et al. Validation of a risk prediction score for proximal neoplasia in colorectal cancer screening: a prospective colonoscopy study. Sci Rep 2016;6:20396.

10. Wong MC, Ching JY, Ng SC, et al. Prediction of proximal advanced neoplasia: a comparison of four existing sigmoidoscopy-based strategies in a Chinese population. Gut 2015;64:776-83.

11. Liwen Huang J, Chen P, Yuan X, Wu Y, Haoxiang Wang $\mathrm{H}$, Chisang Wong M. An algorithm to predict advanced proximal colorectal neoplasia in Chinese asymptomatic population. Sci Rep 2017;7:46493.

12. Wong MC, Ching JY, Chan VC, et al. Colorectal cancer screening based on age and gender: a cost-effectiveness analysis. Medicine (Baltimore) 2016;95:e2739.

13. Naber SK, Kuntz KM, Henrikson NB, et al. Cost effectiveness of age-specific screening intervals for people with family histories of colorectal cancer. Gastroenterology 2017 Sep 27. Epub ahead of print.

14. Wong MC, Ching JY, Chan VC, Sung JJ. The comparative cost-effectiveness of colorectal cancer screening using faecal immunochemical test vs. colonoscopy. Sci Rep 
2015;5:13568.

15. Lin JS, Piper MA, Perdue LA, et al. Screening for colorectal cancer: a systematic review for the U.S. Preventive Services Task Force. Rockville (MD) 2016 Jun. Available from: https://www.ncbi.nlm.nih.gov/pubmedhealth/ PMH0088816/. Accessed 1 Oct 2017.

16. Hassan C, Pooler BD, Kim DH, Rinaldi A, Repici A, Pickhardt PJ. Computed tomographic colonography for colorectal cancer screening: risk factors for the detection of advanced neoplasia. Cancer 2013;119:2549-54.

17. Tóth K, Galamb O, Spisák S, et al. Free circulating DNA based colorectal cancer screening from peripheral blood: the possibility of the methylated septin 9 gene marker [in Hungarian]. Orv Hetil 2009;150:969-77.

18. Zijta FM, Bipat S, Stoker J. Magnetic resonance (MR) colonography in the detection of colorectal lesions: a systematic review of prospective studies. Eur Radiol 2010;20:1031-46.

19. Spada C, Hassan C, Marmo R, et al. Meta-analysis shows colon capsule endoscopy is effective in detecting colorectal polyps. Clin Gastroenterol Hepatol 2010;8:516-22.

20. Graser A, Melzer A, Lindner E, et al. Magnetic resonance colonography for the detection of colorectal neoplasia in asymptomatic adults. Gastroenterology 2013;144:743-750. e2.

21. Rex DK, Adler SN, Aisenberg J, et al. Accuracy of capsule colonoscopy in detecting colorectal polyps in a screening population. Gastroenterology 2015;148:948-57.e2.

22. Wong SH, Kwong TN, Chow TC, et al. Quantitation of faecal Fusobacterium improves faecal immunochemical test in detecting advanced colorectal neoplasia. Gut 2017;66:1441-8.

23. Wong MC, Hirai HW, Luk AK, et al. The knowledge of colorectal cancer symptoms and risk factors among 10,078 screening participants: are high risk individuals more knowledgeable? PLoS One 2013;8:e60366.

24. Wong MC, Ching JY, Hirai HH, et al. Perceived obstacles of colorectal cancer screening and their associated factors among 10,078 Chinese participants. PLoS One 2013;8:e70209.

25. Sung JJ, Choi SY, Chan FK, Ching JY, Lau JT, Griffiths S. Obstacles to colorectal cancer screening in Chinese: a study based on the health belief model. Am J Gastroenterol 2008;103:974-81. 